\title{
Influence of Ionic Liquid 1- butyl-3-methylimidazolium Chloride on the Soil Micro-Ecological System
}

\author{
Yanjie Tong ${ }^{\mathrm{a}}$, Qijun Wang ${ }^{\mathrm{a}, \mathrm{b}}$, Yafan Bi ${ }^{\mathrm{a}}$, Mingke Lei ${ }^{\mathrm{a}}$, Yezi Lva ${ }^{\mathrm{a}}$, Yangyang Liu ${ }^{\mathrm{a}}$ Jiali Liu ${ }^{\mathrm{a}}$, Lili Lu ${ }^{\mathrm{a}}$, \\ Yali $\mathrm{Ma}^{\mathrm{a}}$, Yuanxin $\mathrm{Wu}^{\mathrm{a}}$ and Shengdong $\mathrm{Zhu}^{*, \mathrm{a}}$
}

${ }^{a}$ Key Laboratory for Green Chemical Process of Ministry of Education, Hubei Key Laboratory of Novel Chemical
Reactor and Green Chemical Technology, School of Chemical Engineering and Pharmacy, Wuhan Institute of Technol-
ogy, Wuhan 430073, P.R. China
${ }^{b}$ College of Horticulture and Landscape Architecture, Key Laboratory of Horticulture Science for Southern
Mountainous Regions, Ministry of Education, Southwest University, Chongqing 400715, P.R. China

\begin{abstract}
In order to evaluate the influence of ionic liquid 1- butyl-3-methylimidazolium chloride ([Bmim]Cl) on the soil micro-ecological system, the toxicity of $[\mathrm{Bmim}] \mathrm{Cl}$ to soil microorganisms and its impact on soil physico-chemical properties were investigated. Three soil samples, which were taken from the rape land, nursery land and the broad bean land respectively, were used for this study. The toxicity test results show that the $[\mathrm{Bmim}] \mathrm{Cl}$ inhibited the growth of soil microorganisms including bacteria and actinomycetes. This inhibition became stronger with the $[\mathrm{Bmim}] \mathrm{Cl}$ concentration increasing. The EC50 of soil bacteria was close to that of the Vibrio fischeri, and the EC50 of soil actinomycetes was near to that of the Pseudokirchneriella subcapitata. The soil physico-chemical properties test results indicate that the organic mass and the soluble salts in soil increased with the increase of the $[\mathrm{Bmim}] \mathrm{Cl}$ concentration. The $[\mathrm{Bmim}] \mathrm{Cl}$ also caused the $\mathrm{pH}$ change in the soil micro-ecological system. It suggests that the ionic liquid $[\mathrm{Bmim}] \mathrm{Cl}$ would influence the soil micro-ecological system by inhibiting the growth of soil microorganisms and altering the soil physico-chemical properties when it contaminated the soil system.
\end{abstract}

Keywords: Ionic liquid, [Bmim] Cl, soil micro-ecological system, microorganism, physico-chemical property.

\section{INTRODUCTION}

Ionic liquids (ILs) are a group of new organic salts that exist as liquids at a relatively low temperature $\left(<100{ }^{\circ} \mathrm{C}\right)$. They are composed entirely of ions, typically large organic cations and small inorganic anions $[1,2]$. Interests in ILs have steadily grown in recent years because they have many attractive properties, such as chemical and thermal stability, non-flammability and immeasurably low vapor pressure, which provide the possibility for clean manufacturing in chemical-related industry [3]. Researches on the applications of ILs have become one of the most active areas in green chemistry, the ILs have been widely used in organic synthesis, separation, biotransformation, new material preparation and renewable resource utilization [4-8]. Although most of these applications are still in a laboratory scale, some of them have been coming into pilot or commercial stage since the BASF first successfully used the IL in an industrial scale in $2003[9,10]$. Compared using the traditional volatile organic solvents, the industrial application of ILs can help to reduce air pollution because of their immeas-

*Address correspondence to this author at the Key Laboratory for Green Chemical Process of Ministry of Education, Hubei Key Laboratory of Novel Chemical Reactor and Green Chemical Technology, School of Chemical Engineering and Pharmacy, Wuhan Institute of Technology, Wuhan 430073, P.R. China; Tel: +86-27-87195671; Fax: +86-27-87195671; E-mail: zhusd2003@21cn.con urably low vapor pressure, but it is still possible to release them into environment by accidental spills or effluents, which might cause water or soil pollution [11-13]. Therefore, much attention should be paid on their influence on the environment and ecology when they are used in an industrial scale. The impact of ILs on the environment and ecology is closely related to their bioaccumulation, toxicity and degradability. Based on the reported data on their bioaccumulation, toxicity and degradability in recent years, the ILs might cause water or soil pollution as the commonly used chemicals [11-13]. However, as we know, there are no reports on the influence of ILs on their contaminated soil microecological system. This work is to deal with how the ILs will affect their contaminated soil micro-ecological system. In this work, the most commonly used IL, 1- butyl-3methylimidazolium chloride $([\mathrm{Bmim}] \mathrm{Cl})$ was selected as the model IL. Three soil samples, which were taken from the rape land, nursery land and the broad bean land respectively, were used as the model soil micro-ecological system. The toxicity of $[\mathrm{Bmim}] \mathrm{Cl}$ to soil microorganisms and its impact on soil physico-chemical properties were investigated to evaluate its influence on the soil micro-ecological system.

\section{MATERIALS AND METHODS}

All experiments were carried out three times. The data reported are expressed as the mean values \pm standard deviation. 


\subsection{Materials and Chemicals}

Soil samples were taken from different sites (rape land, nursery land and the broad bean land) in Wuhan, Hubei province, China. All soil samples were collected in the beginning of April in 2010. The soil samples from the rape land, nursery land and the broad bean land were chosen to evaluate the influence of $[\mathrm{Bmim}] \mathrm{Cl}$ on the soil microecological system with different biological and physicochemical characteristics.

Sampling was carried out at 5 randomly chosen points from each site. Samples were collected at a depth of $1 \sim 15$ $\mathrm{cm}$, after removing the top layer. All samples from one site were mixed, then were air-dried, homogenized by sieving to less than $2 \mathrm{~mm}$ to separate roots and large objects, and stored in a polyethylene bag at room temperature for later use.

Each soil sample from one site was divided eight portions, one portion was used as the control, and the remaining seven portions were added the suitable amount of $[\mathrm{Bmim}] \mathrm{Cl}$ to their required $[\mathrm{Bmim}] \mathrm{Cl}$ concentration respectively. In this study, their $[\mathrm{Bmim}] \mathrm{Cl}$ concentration were set at 10000 ppm, $1000 \mathrm{ppm}, 100 \mathrm{ppm}, 10 \mathrm{ppm}, 1 \mathrm{ppm}, 0.1 \mathrm{ppm}$ and 0.01 ppm respectively. These soil samples with different [Bmim $] \mathrm{Cl}$ concentrations were stored in polyethylene bags for 15 days at room temperature, and then they were used to determine their biological and physico-chemical properties.

The $[\mathrm{Bmim}] \mathrm{Cl}$ used in this study was obtained from Henan Lihua Pharmaceutical Co. Ltd., China. All other chemicals employed in this study were of reagent grade and purchased from Wuhan Chemicals \& Reageng Corp., China.

\subsection{Analytical Methods}

\subsubsection{Determination of Biological Properties}

\subsubsection{Determination of the Number of Living Microor- ganisms}

The number of living microorganisms (bacteria or actinomycetes) in soil samples was estimated by viable count on serial spread plates [14]. A series of 10-fold dilution for the sample was prepared starting with $9 \mathrm{ml}$ of sterilized phosphate buffered saline added to $1.0 \mathrm{~g}$ soil sample. The flask was then closed and the contents were stirred for 30 min, and $1.0 \mathrm{ml}$ suspension of sample was added to $9.0 \mathrm{ml}$ of sterilized phosphate buffered saline. The dilutions were repeated to 7 continuous dilutions. Finally, $200 \mu \mathrm{l}$ from each serial dilutions of the sample suspension was spread over an agar plate with beef extract peptone medium for bacteria and an agar plate with Gause's No.1 synthetic medium for actinomycetes. All plates were in triplicates and each soil sample was diluted for three independent measurements. Finally, the plates were incubated two or three days at $28^{\circ} \mathrm{C}$ until colonies appeared ( 2 days for bacteria and 3 days for actinomycetes), and colony forming units (CFU) were count which varied from 30 to 300 .

\subsubsection{Calculation of the EC50 of Microorganisms}

The concentration of added $[\mathrm{Bmim}] \mathrm{Cl}$ which inhibits $50 \%$ of the growth of microorganisms (bacteria and actinomycetes) comparing with the control culture was de- fined as EC50, and it was calculated by a regression method [15].

\subsubsection{Determination of Physico-Chemical Properties}

The organic matter in each soil sample was determined using a $\mathrm{K}_{2} \mathrm{Cr}_{2} \mathrm{O}_{7}-\mathrm{H}_{2} \mathrm{SO}_{4}$ method as described in Chinese National Standard GB9834--88. The soluble salts in each soil sample was measured following the procedures described in Chinese Agricultural Standard NY/T1121.16-2006. The pH value in each soil sample was determined according to the method described in ISO10390-2005.

\section{RESULTS AND DISCUSSION}

\subsection{Toxicity of [Bmim]Cl to the Soil Microorganisms}

The soil microorganisms are an important element in soil micro-ecological system and play a vital role in soil microecological system. The toxicity of $[\mathrm{Bmim}] \mathrm{Cl}$ to the soil $\mathrm{mi}-$ croorganisms is an important part of its influence on the soil micro-ecological system. Table 1 listed the number of microorganisms in different soil samples at different $[\mathrm{Bmim}] \mathrm{Cl}$ concentrations. As indicated in Table 1, the number of microorganisms including bacteria and actinomycetes decreased with the increase of $[\mathrm{Bmim}] \mathrm{Cl}$ concentration for all soil samples. It demonstrated that the [Bmim] Cl could inhibit the growth of such soil microorganisms as bacteria and actinomycetes. Table 2 listed the EC50 of microorganisms including bacteria and actinomycetes of different soil samples. As shown in Table 2, the EC50 values were at relatively lower concentrations for both microorganisms. It indicated that the inhibition of the $[\mathrm{Bmim}] \mathrm{Cl}$ to the growth of both microorganisms was not just simply due to the $\mathrm{pH}$ shift because the $[\mathrm{Bmim}] \mathrm{Cl}$ concentration changed, but it came from its toxicity to these microorganisms. For all soil samples, the EC50 of bacteria was greater than that of actinomycetes. It indicated that actinomycetes in soil was more sensitive to $[\mathrm{Bmim}] \mathrm{Cl}$ than bacteria, that is, the $[\mathrm{Bmim}] \mathrm{Cl}$ had a stronger inhibition on the growth of actinomycetes. For different soil samples, the EC50 of microorganisms including bacteria and actinomycetes existed difference and it showed that the $[\mathrm{Bmim}] \mathrm{Cl}$ had a different extent influence on the growth of the soil microorganisms which come from the soil micro-ecological system with different biological and physico-chemical characteristics. Compared with the reported EC50 of pure cultures [16-19], the EC50 of soil bacteria was close to that of the Vibrio fischeri, and the EC50 of soil actinomycetes was near to that of the Pseudokirchneriella subcapitata. It seems that the toxicity of ILs to soil microorganisms is close to that of some well-investigated organisms, such as Vibrio fischeri and Pseudokirchneriella subcapitata. Whether the ILs toxicity data to these well-investigated organisms can be used to predict the toxicity of ILs to soil microorganisms, further research work are needed because the soil microbial community are far more complicated than the pure cultures. Anyway, the $[\mathrm{Bmim}] \mathrm{Cl}$ would influence the soil micro-ecological system by inhibiting the growth of soil microorganisms including bacteria and actinomycetes. The well-established IL toxicity data of some pure cultures could provide useful information in the prediction of its toxicity to soil microorganisms. 
Table 1. The Number of Microorganisms in Different Soil Samples at Different [Bmim]Cl Concentrations

\begin{tabular}{|c|c|c|c|c|c|c|c|c|c|}
\hline \multirow{2}{*}{} & Soil type & \multicolumn{7}{|c|}{ [Bmim]Cl concentration (ppm) } \\
\cline { 2 - 9 } & & $\mathbf{1 0 0 0 0}$ & $\mathbf{1 0 0 0}$ & $\mathbf{1 0 0}$ & $\mathbf{1 0}$ & $\mathbf{1}$ & $\mathbf{0 . 1}$ & $\mathbf{0 . 0 1}$ & control \\
\hline \hline \multirow{2}{*}{$\begin{array}{c}\text { Bacteria number } \\
\left(10^{7} \mathrm{CFU} . \mathrm{g}^{-1}\right)\end{array}$} & Rape land & $1.30 \pm 0.08$ & $3.20 \pm 0.17$ & $7.65 \pm 0.54$ & $11.06 \pm 1.03$ & $11.51 \pm 0.87$ & $11.22 \pm 0.79$ & $11.75 \pm 0.86$ & $11.80 \pm 0.92$ \\
\cline { 2 - 9 } & Broad bean land & $1.20 \pm 0.23$ & $1.25 \pm 0.35$ & $3.85 \pm 0.045$ & $4.35 \pm 0.46$ & $4.85 \pm 0.63$ & $5.05 \pm 0.73$ & $5.29 \pm 0.39$ & $5.45 \pm 0.47$ \\
\cline { 2 - 9 } & Nursery land & $0.13 \pm 0.01$ & $0.95 \pm 0.02$ & $2.45 \pm 0.39$ & $4.50 \pm 0.81$ & $5.45 \pm 0.43$ & $5.37 \pm 0.54$ & $5.53 \pm 0.61$ & $5.50 \pm 0.79$ \\
\hline \multirow{2}{*}{$\begin{array}{c}\text { Actinomycetes } \\
\text { number } \\
\left(10^{6} \mathrm{CFU} . \mathrm{g}^{-1}\right)\end{array}$} & Rape land & $0.30 \pm 0.02$ & $0.65 \pm 0.06$ & $1.80 \pm 0.02$ & $3.00 \pm 0.31$ & $3.35 \pm 0.54$ & $3.69 \pm 0.43$ & $3.87 \pm 0.49$ & $4.05 \pm 0.75$ \\
\cline { 2 - 9 } & Broad bean land & $1.00 \pm 0.13$ & $2.5 \pm 0.83$ & $3.00 \pm 0.38$ & $5.00 \pm 0.58$ & $9.00 \pm 0.87$ & $9.45 \pm 0.48$ & $10.80 \pm 0.70$ & $11.51 \pm 0.82$ \\
\cline { 2 - 9 } & Nursery land & $0.10 \pm 0.02$ & $0.15 \pm 0.02$ & $0.50 \pm 0.07$ & $0.85 \pm 0.13$ & $1.33 \pm 0.19$ & $1.42 \pm 0.21$ & $1.73 \pm 0.19$ & $1.95 \pm 0.16$ \\
\hline
\end{tabular}

Table 2. The EC50 of Microorganisms of Different Soil Samples

\begin{tabular}{|c|c|c|}
\hline Microorganism type & Land type & EC50 (ppm) \\
\hline \multirow[t]{3}{*}{ Bacteria } & Rape land & $453.93 \pm 20.70$ \\
\hline & Broad bean land & $489.42 \pm 14.47$ \\
\hline & Nursery land & $868.29 \pm 34.31$ \\
\hline \multirow[t]{3}{*}{ Actinomycetes } & Rape land & $81.23 \pm 4.27$ \\
\hline & Broad bean land & $83.13 \pm 2.96$ \\
\hline & Nursery land & $7.50 \pm 1.34$ \\
\hline
\end{tabular}

\subsection{Influence of $[\mathrm{Bmim}] \mathrm{Cl}$ on the Soil Physico-Chemical Properties}

The impact of $[\mathrm{Bmim}] \mathrm{Cl}$ on the soil physico-chemical properties is another important part of its on the soil microecological system besides its toxicity to soil microorganisms. Table 3 listed some important physico-chemical properties of different soil samples at different $[\mathrm{Bmim}] \mathrm{Cl}$ concentra- tions. As indicated in Table $\mathbf{3}$, the organic mass and the soluble salts in soil samples increased with the increase of the $[\mathrm{Bmim}] \mathrm{Cl}$ concentration. This is because the $[\mathrm{Bmim}] \mathrm{Cl}$ itself was an organic compound and it had strong solubility to salts in the soil samples. The [Bmim] Cl also caused the $\mathrm{pH}$ change in the soil micro-ecological system. When the $[\mathrm{Bmim}] \mathrm{Cl}$ concentration was greater than $100 \mathrm{ppm}$, the soil

Table 3. The Physico-Chemical Properties of Different Soil Samples at Different [Bmim]Cl Concentrations

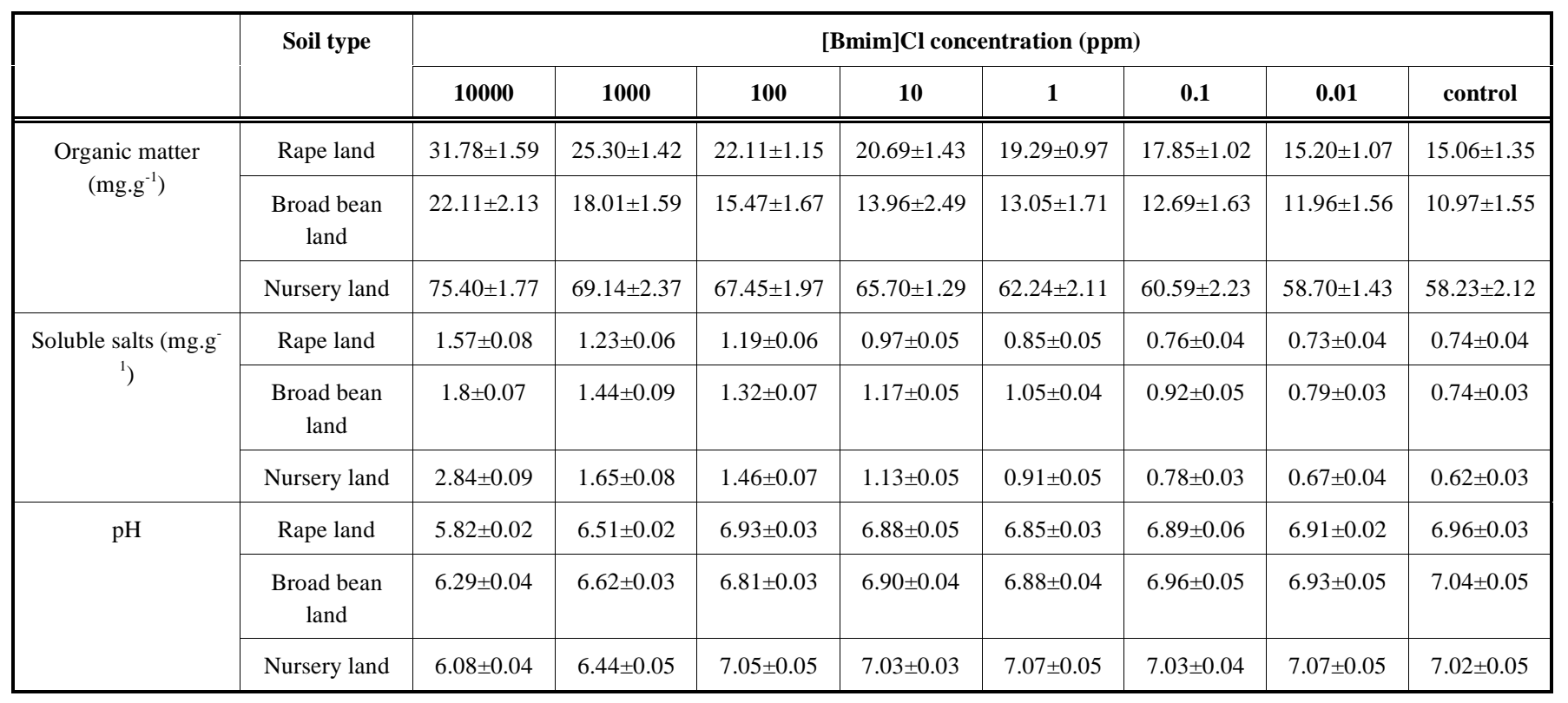


$\mathrm{pH}$ decreased with the $[\mathrm{Bmim}] \mathrm{Cl}$ concentration increasing. When the $[\mathrm{Bmim}] \mathrm{Cl}$ concentration was less than $100 \mathrm{ppm}$, the soil $\mathrm{pH}$ was almost the same as the control. This is the result of interaction between the $[\mathrm{Bmim}] \mathrm{Cl}$ and the soil microorganisms. At lower $[\mathrm{Bmim}] \mathrm{Cl}$ concentration, although the $[\mathrm{Bmim}] \mathrm{Cl}$ itself cause the $\mathrm{pH}$ to decrease because of its acidity, the soil microorganisms had the ability to adjust the soil $\mathrm{pH}$ and the soil $\mathrm{pH}$ could remain almost unchanged. However, at higher $[\mathrm{Bmim}] \mathrm{Cl}$ concentration, the $[\mathrm{Bmim}] \mathrm{Cl}$ cause the $\mathrm{pH}$ to decrease and, at the same time, the soil microorganisms lost the ability to adjust the soil $\mathrm{pH}$ because of its toxicity, the final result was that the soil $\mathrm{pH}$ decreased.

\section{CONCLUSIONS}

This work investigated the toxicity of [ $\mathrm{Bmim}] \mathrm{Cl}$ to soil microorganisms and its impact on soil physico-chemical properties to evaluate its influence on the soil microecological system. The main conclusions are as follows:

1) The $[\mathrm{Bmim}] \mathrm{Cl}$ inhibited the growth of soil microorganisms including bacteria and actinomycetes. This inhibition became stronger with the $[\mathrm{Bmim}] \mathrm{Cl}$ concentration increasing. Based on the EC50 of the soil samples, the actinomycetes were more sensitive to the $[\mathrm{Bmim}] \mathrm{Cl}$ than the bacteria.

2) The organic mass and the soluble salts in soil increased with the increase of the $[\mathrm{Bmim}] \mathrm{Cl}$ concentration. The $[\mathrm{Bmim}] \mathrm{Cl}$ also caused the $\mathrm{pH}$ change in the soil micro-ecological system.

3) The $[\mathrm{Bmim}] \mathrm{Cl}$ would influence the soil microecological system by inhibiting the growth of soil microorganisms and altering the soil physico-chemical properties when it contaminated the soil system.

\section{CONFLICT OF INTEREST}

None declared.

\section{ACKNOWLEDGEMENTS}

This work was support by Hubei Key Laboratory of Novel Chemical Reactor and Green Chemical Technology (RGCT201005) and the National Natural Science Foundation of China (No. 21176196). We thank Dr Shixue Zheng
(Huazhong Agricultural University, Wuhan, China) for his assistance in experiment work.

\section{REFERENCES}

[1] Wasserscheid P, Stark. Handbook of Green Chemistry: Green Solvents, Vol.6-Ionic Liquid. Wiley-VCH, 2010.

[2] Zhang S, Xu C, Lv X, Zhou Q. Ionic liquid \& green chemistry. China Science Press, Beijing, 2009.

[3] Rogers RD, Seddon KR. Ionic liquids: Industrial applications for green chemistry. Oxford University Press, England, UK, 2002.

[4] Wasserscheid P, Welton T. Ionic Liquid in Synthesis $\left(2^{\text {nd }}\right.$ edn). Wiley-VCH, 2007.

[5] Zhao H, Xia SQ, Ma PS. Use of ionic liquids as green solvents for extractions. J Chem Technol Biotechnol 2005; 80: 1089-96.

[6] Rantwijk FV, Sheldon RA. Biocatalysis in ionic liquids. Chem Rev2007; 107: 2757-85.

[7] Zhu S, Wu Y, Chen Q, et al. Dissolution of cellulose with ionic liquids and its applications: a mini-review. Green Chem 2006; 8: 325-7.

[8] Zhu S. Use of ionic liquids for the efficient utilization of lignocellulosic materials. J Chem Technol Biotechnol 2008; 83: 777-9.

[9] Freemantle M. BASF's smart ionic liquid. Chem Eng News 2003; 81: 9 .

[10] Plechkova NV, Seddon KR. Applications of ionic liquids in chemical industry. Chem Soc Rev 2008; 37: 123-50.

[11] Zhu S, Wu Y, Chen Q, Chi R, Shen X, Yu Z. A mini-review on greenness of ionic liquids. Chem Biochem Eng Q 2009; 23: 20711.

[12] Pham TPT, Cho CW, Yun YS. Environmental fate and toxicity of ionic liquids: a review. Water Res 2010; 44: 352-72.

[13] Zhao D, Liao Y, Zhang Z. Toxicity of ionic liquids. Clean-Soil, Air, Water, 2007; 35: 42-8.

[14] Zheng S, Yao J, Zhao B, Yu Z. Influence of agriculture practice on soil microbial activity measured by microcalorimetry. Eur J Soil Biol 2007; 43: 151-7

[15] Lee SM, Chang WJ, Choi AR, Koo YM. Influence of ionic liquids on the growth of Escherichia coli. Korean J Chem Eng 2005; 22: 687-90.

[16] Couling DJ, Bernot RJ, Docherty KM, Dixon JK, Maginn EJ. Assessing the factors responsible for ionic liquid toxicity to aquatic organisms via quantitative structure-property relationship modeling. Green Chem 2006; 8: 82-90.

[17] Garcia MT, Gathergood N, Scammells PJ. Biodegradable ionic liquids. Part II: effect of the anion and toxicology. Green Chem 2005; 7: 9-14.

[18] Docherty KM, Kulpa CF. Toxicity and antimicrobial activity of imidazolium and pyridinium ionic liquids. Green Chem 2005; 7: $185-9$.

[19] Wells AS, Coombe VT. On the freshwater ecotoxicity and biodegradation properties of some common ionic liquids. Org Pro Res Dev 2006; 10: 794-8. (http://creativecommons.org/licenses/by-nc/3.0/) which permits unrestricted, non-commercial use, distribution and reproduction in any medium, provided the work is properly cited 